\title{
Interplanetary Sample Return Missions Using Radioisotope Electric Propulsion
}

\author{
R. Williams", Y. Gao ${ }^{\dagger}$, C.A. Kluever ${ }^{\ddagger}$ \\ University of Missouri-Columbia, Columbia, Missouri 65211 \\ M. Cupples ${ }^{\$}$, J. Belcher ${ }^{* *}$ \\ Science Applications Intemational Corporation, Huntsville, Alabama 35806
}

Solar electric propulsion (SEP) is being used for a variety of planetary missions sponsored by ESA, JAXA, and NASA and nuclear electric propulsion (NEP) is being considered for future, flagship-class interplanetary missions. Radioisotope electric propulsion (REP) has recently been shown to effectively complement SEP and NEP for missions to high-AU targets with modest payload requirements. This paper investigates the application of an advanced REP for a sample return from the comet Tempel 1. A set of mission and system parameters are varied with the goal of quantifying their impact on total mission payload. Mission parameters considered include trip-time and Earth retum entry interface speed of the sample return system. System parameters considered include launch vehicle, power level of spacecraft at beginning of mission, and thruster specific impulse. For the baseline case of Atlas 401 and REP power level of $750 \mathrm{~W}$, the mission time was 12 years, the payload was $144 \mathrm{~kg}$, and the missions optimized to a single specific impulse generally within Hall ion thruster range. Other cases were investigated in support of graduate studies, and include the larger Atlas 551 launch vehicle and extended power level to $1 \mathrm{~kW}$. The Atlas 551 cases tended to optimize dual specific impulses generally in the Hall ion thruster range for both legs of the mission. A power level of at least $1-\mathrm{kW}$ and trip-time of approximately 11 years was required to obtain a total science payload close to $320 \mathrm{~kg}$ for the Atlas 401 launch vehicle. An Atlas 551 launch vehicle yielded a science payload of approximately $540 \mathrm{~kg}$ for the case of $1-\mathrm{kW}$ of power and an 11-year trip time, and nearly $250 \mathrm{~kg}$ of science payload for the case of $1-\mathrm{kW}$ of power and a 6-year trip time. Results are also reported indicating the performance ramifications of meeting a reduced Earth entry interface velocity constraint.

\section{Introduction}

$E^{l e t e n t a n}$ lectric propulsion (EP) is being used increasingly for planetary missions. Solar electric propulsion (SEP) has recently been successfully demonstrated by NASA's Deep Space $1^{1}$, ESA's SMART $1^{2}$, and JAXA's HAYABUSA ${ }^{3}$ spacecraft. Nuclear electric propulsion (NEP) is also being considered for missions requiring large payload masses and powers. SEP and NEP have been shown to provide major values for a range of planetary missions. In addition, radioisotope electric propulsion (REP) has been shown to be a strong candidate for planetary missions with small to modest payloads traveling to high AU. Early studies by Noble ${ }^{4,5,6}$ and subsequent NASA ${ }^{7,8,9}$ work analyzed REP efficacy to the outer solar system and near-interstellar space. Advantages of REP include a power source that is basically insensitive to AU, enables the accomplishment of modest missions in reasonable mission times, and has a legacy of successful applications on planetary missions.

This paper investigates the feasibility of using REP for a sample return mission to comet Tempel 1 in the 2010 time frame. For this analysis, two-body dynamics govern the orbit transfer, and the propulsion system is optimized for parameters such as launch energy $\left(C_{3}\right)$ and the REP specific impulse $\left(I_{\mathrm{sp}}\right)$. Several mission scenarios that maximize the mass returned to Earth for a range of initial REP power levels and sample return earth entry speeds are

\footnotetext{
Graduate Research Assistant, Mechanical and Aerospace Engineering Department, University of Missouri-Columbia, Columbia, Missouri, 65211. E-mail: rcw9f4@mizzou.edu

${ }^{\dagger}$ Graduate Research Assistant, Mechanical and Aerospace Engineering Department, University of Missouri-Columbia, Columbia, Missouri, 65211. E-mail: yg386@mizzou.edu

¥ Associate Professor, Mechanical and Aerospace Engineering Department, University of Missouri-Columbia, Columbia, Missouri, 65211. Associate Fellow ALAA. E-mail: KlueverC@missouri.edu

Lead Systems Engineer, Science Applications International Corporation, Huntsville, Alabama, 35806. E-mail: cupplesm@saic.com

${ }^{* *}$ Engineer, Science Applications International Corporation. Huntsville, Alabama, 35806. E-mail: belcherj@saic.com
} 
obtained. Using systems analysis, the spacecraft size, propulsion subsystems, and net payload are obtained for the various mission cases considered. The baseline case shown in this paper represents early resuits in support of a study performed for NASA's Science Mission Directorate's Radioisotope Electric Propulsion Program ${ }^{10}$. This paper also reports later results obtained through support of graduate work at the University of Missouri.

\section{System and Mission Analyses}

\section{A. System Approaches}

The overall spacecraft model is based on state-of-art vehicles such as Mercury MESSENGER and DAWN. The REP power system (RPS) consists of a set of radioisotope-based general-purpose heat sources, a Stirling energy conversion system that transforms the heat to electrical power, power conditioning components, and distribution cabling. The RPS power source was assumed to be a second-generation concept with a specific power of $8 \mathrm{~W} / \mathrm{kg}$ that provided power to the electric propulsion system and a fixed $100 \mathrm{~W}$ to the spacecraft. For all calculations, it is assumed that the REP power degrades at a constant rate of $1.15 \%$ per year.

The electric propulsion system consists of a power-processing unit that converts the bus power to the required thruster operating currents and voltages, the electric thrusters, and cable harnesses from the power processors to the electric thrusters. The electric propulsion hardware masses were provided by the Glenn Research Center. The system includes two PPUs, one being a spare, with fixed specific masses of $12 \mathrm{~kg} / \mathrm{kW}$. The thruster specific masses are 3.25 $\mathrm{kg} / \mathrm{kW}, 3.00 \mathrm{~kg} / \mathrm{kW}$, and $2.75 \mathrm{~kg} / \mathrm{kW}$ for $500 \mathrm{~W}, 750 \mathrm{~W}$, and $1000 \mathrm{~W}$ respectively. The thruster is an advanced design assumed to have an operating life of $30,000 \mathrm{hrs}$. The thruster specific impulse is limited to a range of 1000 to $4000 \mathrm{~s}$, and a simple parametric relation is used to compute thruster efficiency $(\eta)$ as a function of $I_{\mathrm{sp}}$ :

$$
\eta=\frac{(b b)\left(d d^{2}\right)}{d d^{2}+\left(g I_{s p}\right)^{2}}
$$

This parametric relationship was developed by the Glenn Research Center specifically for this study. Thrust magnitude $(T)$ is computed as a function of input power $(P)$, efficiency $(\eta)$, and specific impulse:

$$
T=\frac{2 \eta P}{g I_{s p}}
$$

This range of $I_{\mathrm{sp}}$ covers both the theoretical ranges of a Hall thruster (defined for this study as $1000 \mathrm{~s}$ to $2500 \mathrm{~s}$ ) and of a gridded ion thruster (defined for this study as $2500 \mathrm{~s}$ to $4000 \mathrm{~s}$ ). An actual thruster cannot operate over the entire $I_{\mathrm{sp}}$ range selected. Trajectories that have an outbound $I_{\mathrm{sp}}$ in one range and an inbound $I_{\mathrm{sp}}$ in another range do not include a system mass penalty, which would be needed to reflect the realities of having two separate propulsion systems. It is assume that the REP power degrades at a constant rate of $1.15 \%$ loss per year.

Injected mass for the Atlas 401 and 551 launch vehicles is computed as a function of launch energy, as shown in Fig. 1. 


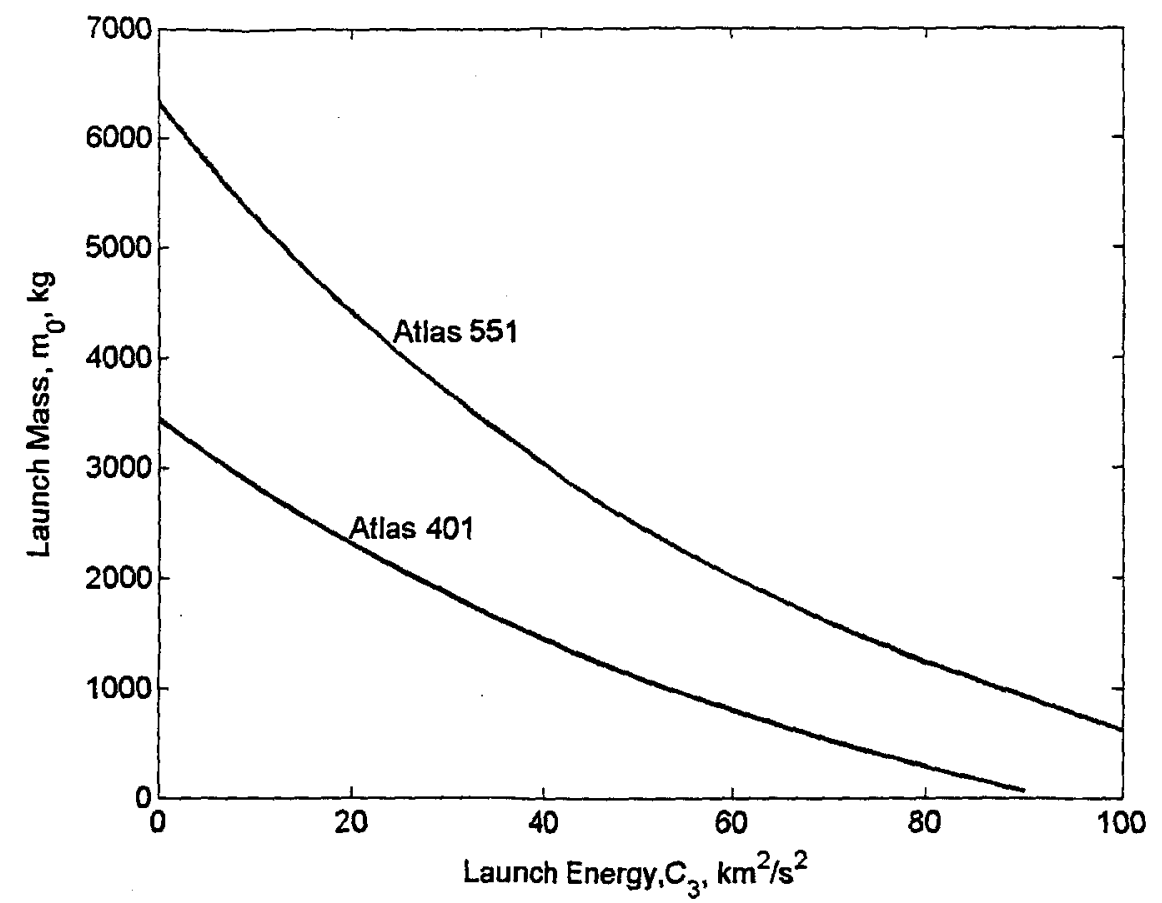

Figure 1. Launch mass vs. $C_{3}$ for Atlas 401 and Atlas 551

\section{B. Mission Profile and Assumptions}

The interplanetary trajectory begins with injection into heliocentric space by either an Atlas 401 (baseline mission) or Atlas 551 launch vehicle, providing the spacecraft with the desired launch energy $\left(C_{3}\right)$. Figure 1 shows the capabilities of both launch vehicles. Immediately after leaving geocentric space, the ion propulsion system is started and a powered arc is initiated. It is assumed that the spacecraft is equipped with multiple xenon ion engines that have performance and lifetime characteristics similar to a small advanced Hall or gridded ion thruster. Because the REP system can only supply 500-1000 W of power for the EP system, it is assumed that only a single ion thruster is operated at a time. After a prolonged burn, erosion eventually renders the working thruster unusable, and the next thruster is started to continue the powered arc. Therefore, thruster lifetime issues or maximum propellant limitations do not impose additional constraints on the trajectory design as long as total engine mass is properly accounted for.

After a continuously powered outbound cruise phase, the spacecraft matches the heliocentric orbit of comet Tempel 1 and spirals down to a stable orbit about the comet. A small probe (maneuvering sampling system) descends to the comet surface and returns samples to the orbiting primary spacecraft. It is assumed that the main spacecraft leaves $50 \mathrm{~kg}$ of the sampling system at the comet after sampling operations. A 60-day stay-time constraint at Tempel 1 is imposed in order to account for rendezvous, science, and sampling operations. After a minimum stay time of 60 days, the Earth-return leg is initiated and thrusting is maintained until the spacecraft reaches proper orbital conditions for a ballistic coasting trajectory to Earth. The sample return mission ends with the sample return system's direct ballistic entry into Earth's atmosphere. The primary spacecraft is assumed to be diverted from an intercept with Earth into a heliocentric orbit.

\section{Trajectory Optimization}

The comet sample return mission design objective is to maximize the science payload mass. The trajectory design variables include launch date, injection point into optimal Earth departure condition, outbound and return powered arc durations, thrust direction during the powered arcs, specific impulse for the outbound and return legs, Tempel 1 rendezvous date, stay time at the comet, and Earth-return date. The powered equations of motion are 
numerically integrated by using a fixed-step, fourth-order Runge-Kutta routine in a heliocentric frame. Coast arcs are computed analytically. Therefore, the outbound and inbound trajectories begin and end at the respective body's sphere of influence. Details of the numerical simulation of the interplanetary trajectory are presented in Ref. 10.

Numerical solutions of the maximum-delivered-mass problem are obtained by using a direct trajectory optimization method (DTOM) ${ }^{11}$. The optimal control problem is replaced by a nonlinear programming problem, which is solved by using sequential quadratic programming ( $\mathrm{SQP}$ ), a constrained parameter optimization method. The SQP code used here is described in Ref. 12 and uses forward finite differences to compute gradient information. The thrust direction is defined by three direction cosines relative to a rotating radial-transverse-normal frame and the time histories of these direction cosines are parameterized by linear interpolation through a set of discrete nodes. Midpoint rendezvous conditions are imposed by six SQP equality constraints that maintain a match between the orbital elements of the spacecraft and Tempel 1 at the rendezvous date. Three additional SQP equality constraints maintain a heliocentric position match between the spacecraft and Earth at the terminal end of the trajectory (ballistic entry). Finally, a single inequality constraint is imposed on the hyperbolic approach speed at the Earth's sphere of influence in order to maintain feasible limits on the entry speed. The orbital elements of the Earth and Tempel 1 are computed using an accurate solar system ephemeris. ${ }^{13}$

\section{Analyses Results}

\section{A. Payload Variation with Varying Initial Power}

Our initial trials involve computing optimal sample return missions over a range of initial power levels for the REP system. The initial beginning-of-life power is set to 500,750 , and $1000 \mathrm{~W}$ and the optimal trajectories that maximize science payload mass at Earth return are obtained. For these initial cases, it is assumed that the hyperbolic approach speed for the ballistic Earth-return leg is constrained to $\leq 10.7 \mathrm{~km} / \mathrm{s}$, which corresponds to $15.4 \mathrm{~km} / \mathrm{s}$ at entry interface ( $125 \mathrm{~km}$ above the Earth's surface). In a later section of this report, results are shown that indicate the mission impact of reducing the Earth entry interface speed to $\leq 13 \mathrm{~km} / \mathrm{s}$. In addition, the launch energy is fixed to obtain optimal missions over a fixed set of $C_{3}$.

Figure 2 shows a representative mission profile for the case using the Atlas 401, where initial power is $750 \mathrm{~W}$ and $C_{3}=36 \mathrm{~km}^{2} / \mathrm{s}^{2}$. Because the REP power is so low, the spacecraft requires over two revolutions about the sun (with continuous thrust) before it sufficiently increases energy to reach Tempel 1. After the 60-day stay time at Tempel 1, a single powered arc (one-half revolution) decreases energy and the spacecraft begins the transfer back to Earth. The final phase of the mission is a ballistic coasting trajectory that ends with an Earth atmospheric entry speed of $15.4 \mathrm{~km} / \mathrm{s}$. The total trip time is about 11 years (as compared to 12 years for the baseline mission), and this mission profile and relative geometry appear to provide a good local minimum for the launch year of 2010.

Figure 3 presents the maximum spacecraft science payload as a function of launch energy for the three initial power levels of the Atlas 401. It is clearly seen that an increase in power level for the REP spacecraft results in greater science payload mass. For each power level, there exists an optimal launch energy, and the optimal $C_{3}$ tends to decrease as the power increases. These trends in optimal final mass and optimal launch energy are easily explained: higher power increases thrust magnitude, and therefore the REP system can perform a greater share of the required orbit transfer, which subsequently reduces the magnitude of the energy contribution from the launch vehicle. Therefore, the decrease in launch energy increases the injected mass, which ultimately increases the payload at Earth return. 


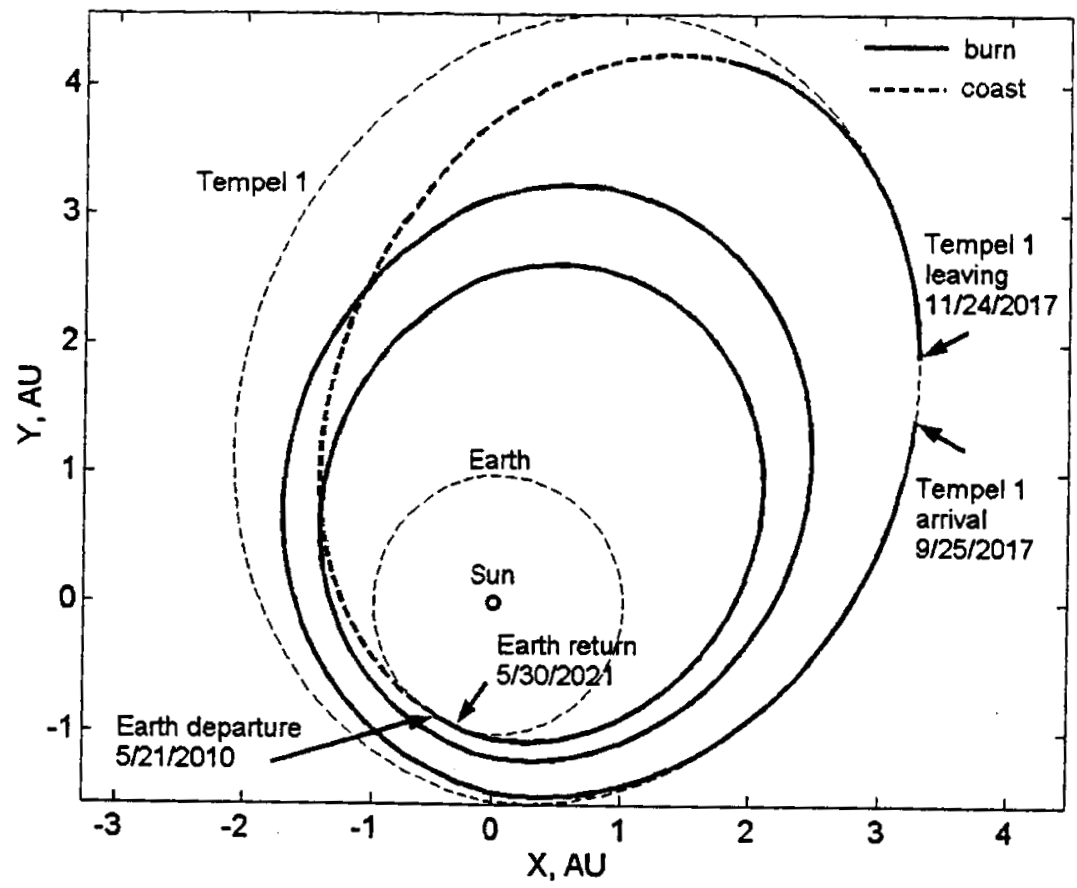

Figure 2. Representative trajectory for Tempel 1 sample return mission: initial power of $750 \mathrm{~W}$, Atlas 401 with $C_{3}=36 \mathrm{~km}^{2} / \mathrm{s}^{2}$

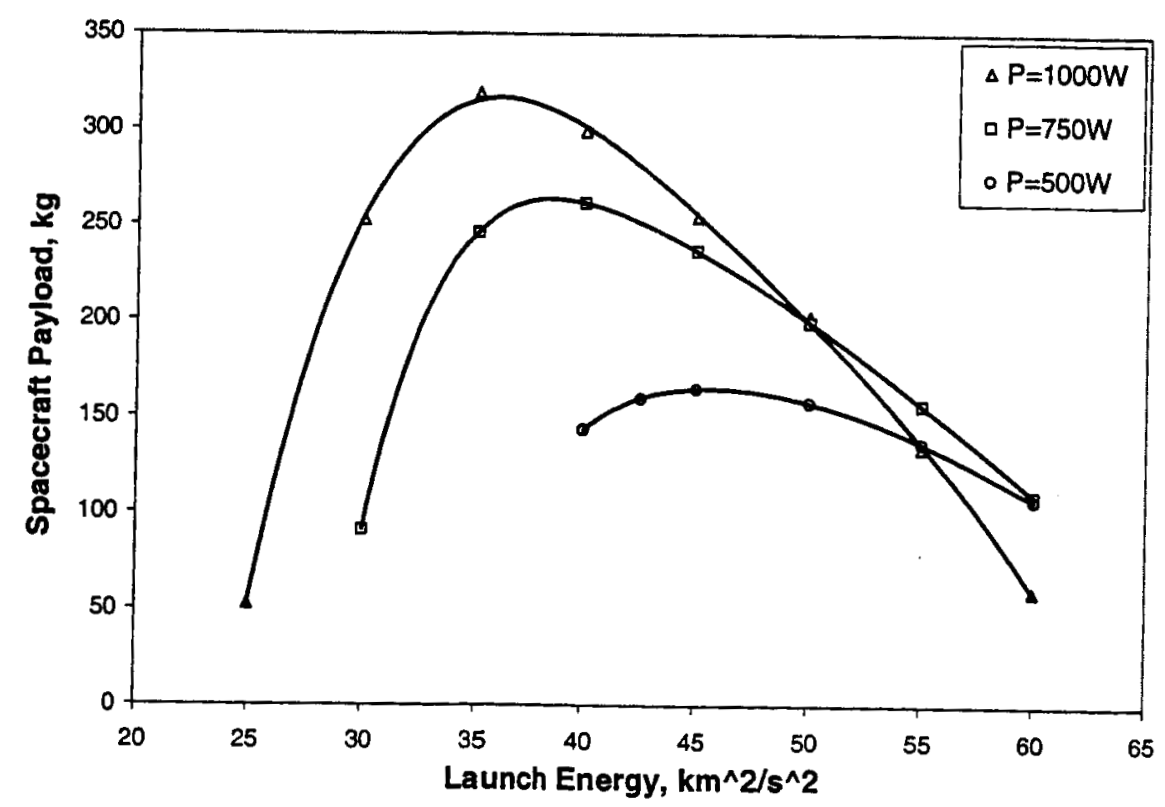

Figure 3. Maximum payload mass for different initial power levels and launch energies (Atlas 401). 
Table 2 summarizes the best mission designs for the Atlas 401 for each initial power level and provides the mission characteristics for the three values of $C_{3}$ that give the best final mass solution for each power level shown in Fig. 5. A distinct trend among the different missions became apparent: all missions (regardless of initial power) use very nearly the same mission profile with the same launch date, rendezvous date, Earth-arrival date, and 11-yr trip time. Therefore, relative geometry between Earth and Tempel 1 in the 2010 opportunity dictates the best trajectory. Furthermore, when power level is increased, the REP system is able to operate at a higher specific impulse, which increases the overall efficiency of the transfer and reduces the xenon propellant requirement. For example, note that when initial power is $500 \mathrm{~W}$, the mission requires an $I_{\mathrm{sp}}$ of $1267 \mathrm{~s}$, which is close to the lower bound of $1000 \mathrm{~s}$. This low specific impulse is required to increase thrust in order to reach Tempel 1 with a continuous powered arc and the optimal flight profile shown in Fig. 2 (i.e., two and one-quarter revolutions about the sun for the optimal rendezvous position with Tempel 1). As power is increased, optimal $I_{\mathrm{sp}}$ settings increase.

Table 2. Mission parameters for optimal sample return missions using the Atlas 401 Earth Entry Speed $=15.4 \mathrm{~km} / \mathrm{s}$

\begin{tabular}{cccccccc}
\hline $\begin{array}{c}\text { Initial } \\
\text { Power } \\
(\mathbf{W})\end{array}$ & $\begin{array}{c}\mathbf{C}_{\mathbf{3}} \\
\left(\mathbf{k m}^{2} / \mathbf{s}^{2}\right)\end{array}$ & $\begin{array}{c}\text { Launch } \\
\text { Date }\end{array}$ & $\begin{array}{c}\text { Trip Time } \\
(\mathbf{y r s})\end{array}$ & $\begin{array}{c}\mathbf{m}_{\mathbf{0}} \\
(\mathbf{k g})\end{array}$ & $\begin{array}{c}\mathbf{m}_{\text {prop }} \\
(\mathbf{k g})\end{array}$ & $\begin{array}{c}\text { Payload } \\
(\mathbf{k g})\end{array}$ & $\begin{array}{c}\boldsymbol{I}_{\text {sp }} \\
(\mathbf{s})\end{array}$ \\
\hline 500 & 42.6 & $5 / 28 / 2010$ & 11.01 & 1359 & 614 & 158 & 1267 \\
750 & 36.9 & $5 / 23 / 2010$ & 11.03 & 1572 & 577 & 259 & 1773 \\
1000 & 34.3 & $5 / 20 / 2010$ & 11.04 & 1675 & 514 & 316 & 2316 \\
\hline
\end{tabular}

Next, optimal missions were determined using the Atlas 551 launch vehicle. Again, hyperbolic approach speed at Earth was constrained to $10.7 \mathrm{~km} / \mathrm{s}(15.4 \mathrm{~km} / \mathrm{s}$ at Earth entry interface). Table 3 summarizes these best mission designs for the optimal launch energy for a range of initial power levels. The larger Atlas 551 vehicle permits different options for rendezvous dates and trip times. For example, the larger launch vehicle allows for cases with significantly higher launch energy than the Atlas 401 . The higher launch energy effectively eliminates one revolution about the sun on the outbound leg, and subsequently the trip time can be reduced by 3 or 6 years for the each of the cases. All missions have an Earth-return date of early June in the years 2022, 2019, and 2016. Figure 4 shows a trajectory example for the previously mentioned 6 year direct outbound transfer to Tempel 1 for the case where initial power is $1000 \mathrm{~W}$. Note that for the outbound and return legs, the total transfer angle is around 360 deg. The science payload mass for this high-power case is only modestly less than the corresponding Atlas 401 case, but the trip time has been cut nearly in half from 11 years to 6 years. Table 3 also shows an interesting case (power level is $1000 \mathrm{~W}$ ) where the trip time is 11 years, and the payload has reached $535 \mathrm{~kg}$, which is almost double the payload of the corresponding Atlas 401 case.

Table 3. Mission parameters for optimal sample return missions using the Atlas 551 Earth Entry Speed $=15.4 \mathrm{~km} / \mathrm{s}$

\begin{tabular}{cccccccc}
\hline $\begin{array}{c}\text { Initial } \\
\text { Power } \\
(\mathbf{W})\end{array}$ & $\begin{array}{c}\mathbf{C}_{\mathbf{3}} \\
\left(\mathbf{k m}^{2} / \mathbf{s}^{2}\right)\end{array}$ & $\begin{array}{c}\text { Launch } \\
\text { Date }\end{array}$ & $\begin{array}{c}\text { Trip Time } \\
(\mathbf{y r s})\end{array}$ & $\begin{array}{c}\mathbf{m}_{\mathbf{0}} \\
(\mathbf{k g})\end{array}$ & $\begin{array}{c}\mathbf{m}_{\text {prop }} \\
\mathbf{( k g )}\end{array}$ & $\begin{array}{c}\text { Payload } \\
(\mathbf{k g})\end{array}$ & $\begin{array}{c}\mathbf{I}_{\mathbf{s p}} \\
\text { (outbound/ } \\
\text { return legs) } \\
(\mathbf{s})\end{array}$ \\
\hline 500 & 70 & $5 / 31 / 2010$ & 11.01 & 1612 & 780 & 184 & $1000 / 1834$ \\
750 & 48 & $6 / 3 / 2010$ & 11.00 & 2575 & 1261 & 361 & $1000 / 1967$ \\
1000 & 40 & $5 / 31 / 2010$ & 11.01 & 3057 & 1330 & 535 & $1243 / 2422$ \\
500 & 79 & $5 / 10 / 2010$ & 9.07 & 1260 & 692 & 51 & $1000 / 1089$ \\
750 & 66 & $5 / 2 / 2010$ & 9.09 & 1745 & 887 & 151 & $1232 / 1212$ \\
1000 & 64 & $4 / 30 / 2010$ & 9.09 & 1850 & 764 & 257 & $1739 / 1592$ \\
500 & 85 & $5 / 9 / 2010$ & 6.08 & 1054 & 526 & 54 & $1000 / 1189$ \\
750 & 68 & $5 / 1 / 2010$ & 6.10 & 1678 & 858 & 142 & $1003 / 1234$ \\
1000 & 61 & $4 / 24 / 2010$ & 6.12 & 1953 & 869 & 247 & $1300 / 1491$
\end{tabular}




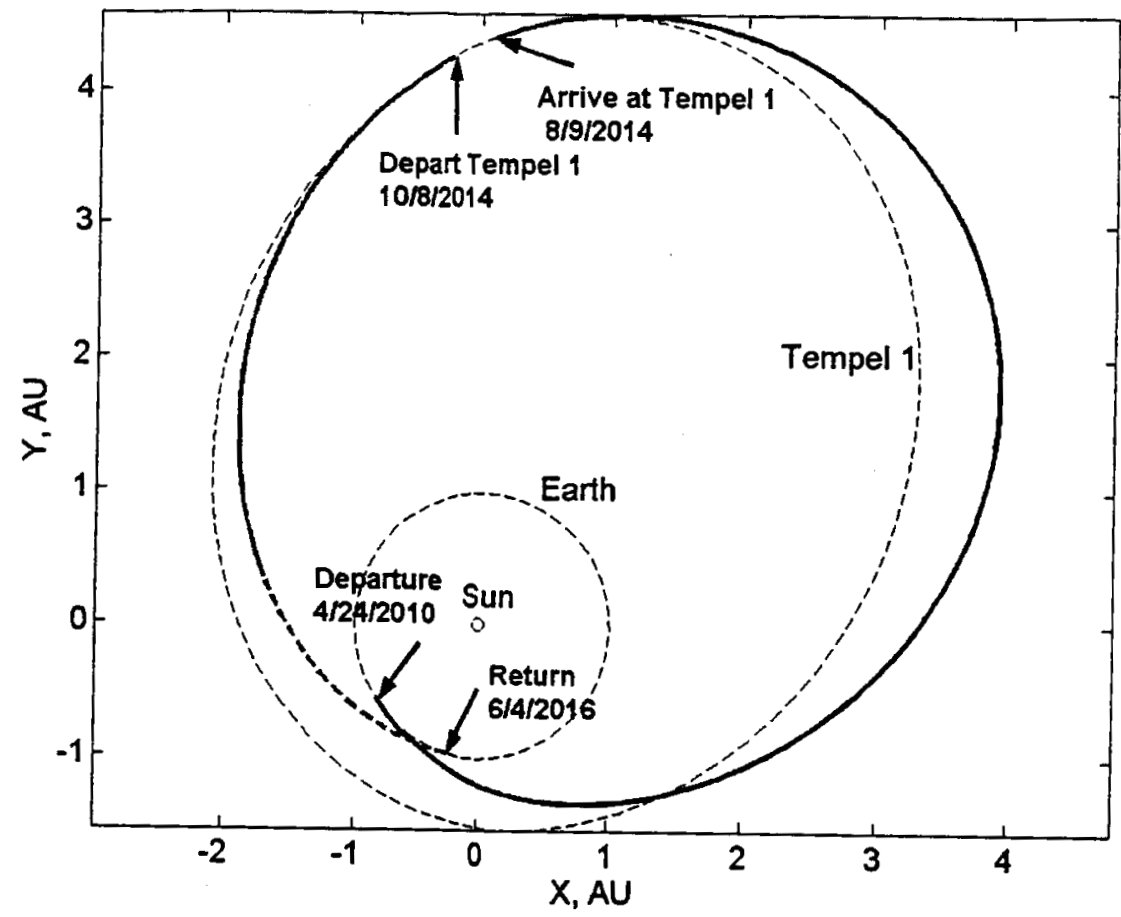

Figure 4. Six-year Tempel 1 sample return mission: initial power of $1000 \mathrm{~W}$, Atlas 551 with $C_{3}=61 \mathrm{~km}^{2} / \mathrm{s}^{2}$

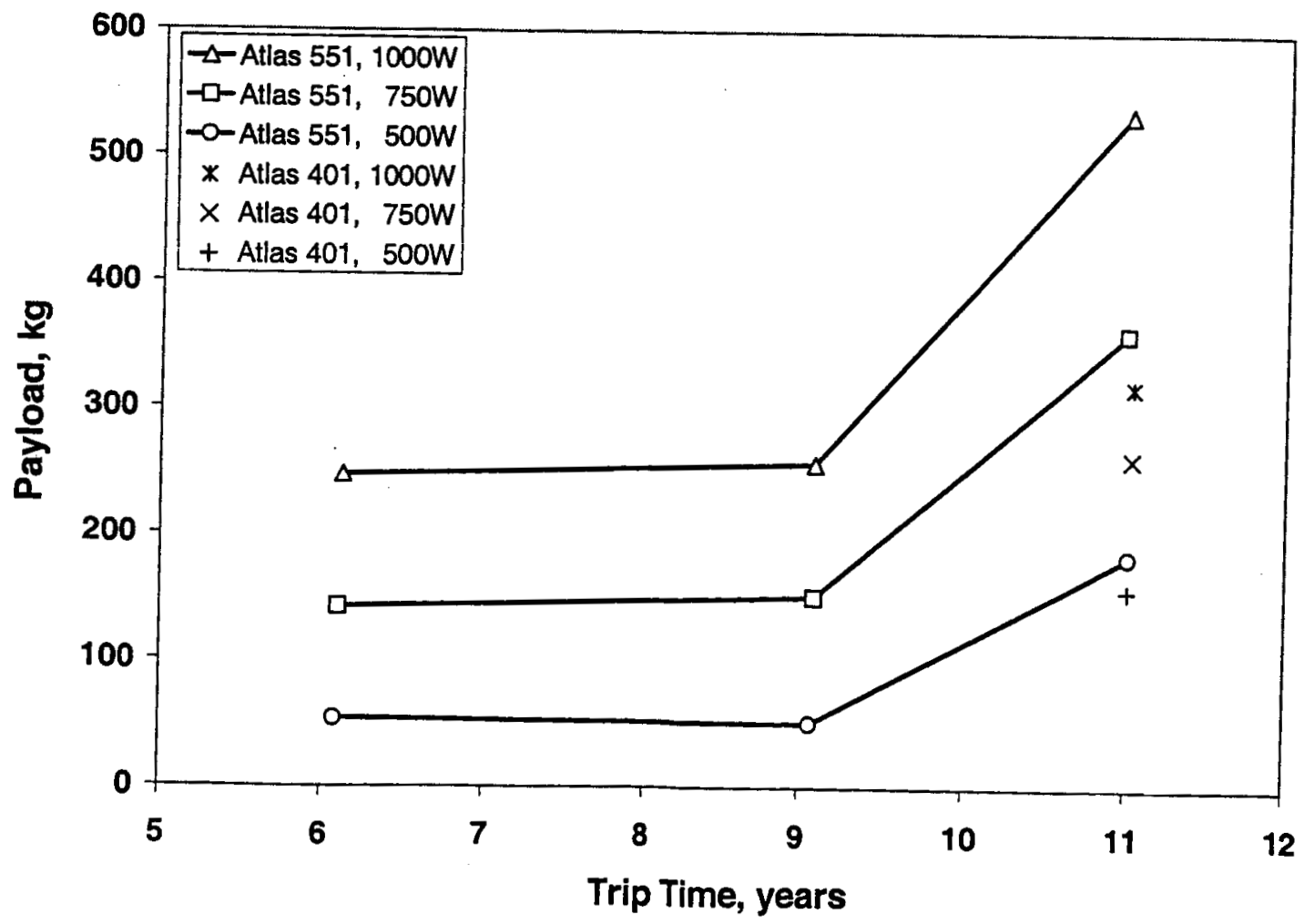

Figure 5. Trip Time versus payload trade for Atlas 551 and Atlas 401 while varying power levels 
The data of Tables 1 and 2 are now organized into a payload versus trip time plot shown in Figure 5. A comparison of the Atlas 401 and 551 launch vehicles shows that for the 551 launch vehicle, a significant decrease in trip time can be realized over the Atlas 401 cases. Likewise, for the same trip time, the 551 can deliver more science payload mass than the 401 . Yet in the case of $500 \mathrm{~W}$ REP, the difference in science payload delivery capability is minimal. For the 11 year trip time, the $750 \mathrm{~W}$ REP spacecraft and the 551 launch vehicle can provide significantly more payload than the corresponding case for the 401 launch vehicle. The $1000 \mathrm{~W}$ spacecraft injected by the 551 launch vehicle can deliver about the same payload as the $1000 \mathrm{~W}$ Atlas 401 case, but at a very significant 6 year reduction in trip time. If large payloads (on the order of $500 \mathrm{~kg}$ ) are required, then a longer 11 year trip time and the maximum $1000 \mathrm{~W}$ of power will be needed.

\section{B. Payload Variations for Earth Return Entry Interface Speed}

Next, several optimal sample return missions were obtained for a range of constraints on hyperbolic approach speed at Earth return. Table 4 shows a parametric study on reducing entry speed at Earth interface for the Atlas 401 with initial REP power of $1000 \mathrm{~W}$. These 11-yr mission cases will allow us to observe the trends in payload mass when Earth entry speed is varied. Note that entry speed can be reduced by adding trip time for another revolution about the sun, resulting in an energy reduction. Figure 6 shows a representative 13-yr mission that reduces the reentry speed to $12.5 \mathrm{~km} / \mathrm{s}$, which is closer to the reentry speed of the Apollo capsule. The baseline entry speed of $15.4 \mathrm{~km} / \mathrm{s}$ is aggressive and may not be achievable by 2010 . Note that an additional revolution around the sun is needed for this additional energy depletion before reentry. The payload for this 13 -year case is, however, greatly reduced to an inadequate $53 \mathrm{~kg}$. Table 4 shows that the final mass dramatically decreases as the limit on reentry speed is reduced.

Table 4. Optimal sample return missions using the Atlas 401, initial power level of $1000 \mathrm{~W}$, and reduced $\mathrm{V}_{\mathrm{EI}}$

\begin{tabular}{ccccccc}
\hline $\begin{array}{c}\text { Entry } \\
\text { Speed, } \\
(\mathbf{k m} / \mathbf{s})\end{array}$ & $\begin{array}{c}\mathbf{C}_{\mathbf{3}} \\
\left(\mathbf{k m}^{2} / \mathbf{s}^{\mathbf{2}}\right)\end{array}$ & $\begin{array}{c}\text { Launch } \\
\text { Date }\end{array}$ & $\begin{array}{c}\text { Trip } \\
\text { Time } \\
(\mathbf{y r s})\end{array}$ & $\begin{array}{c}\mathbf{m}_{\mathbf{0}} \\
(\mathbf{k g})\end{array}$ & $\begin{array}{c}\mathbf{m}_{\text {prop }} \\
(\mathbf{k g})\end{array}$ & $\begin{array}{c}\text { Payload } \\
(\mathbf{k g})\end{array}$ \\
\hline 15.0 & 34 & $5 / 19 / 2010$ & 11.04 & 1673 & 514 & 314 \\
14.5 & 35 & $5 / 19 / 2010$ & 11.04 & 1664 & 518 & 307 \\
14.0 & 35 & $5 / 20 / 2010$ & 11.02 & 1657 & 535 & 291 \\
13.5 & 35 & $5 / 22 / 2010$ & 11.04 & 1636 & 583 & 247 \\
13.0 & 35 & $6 / 7 / 2010$ & 12.96 & 1668 & 826 & 100 \\
12.5 & 35 & $6 / 8 / 2010$ & 12.97 & 1623 & 846 & 53 \\
\hline
\end{tabular}




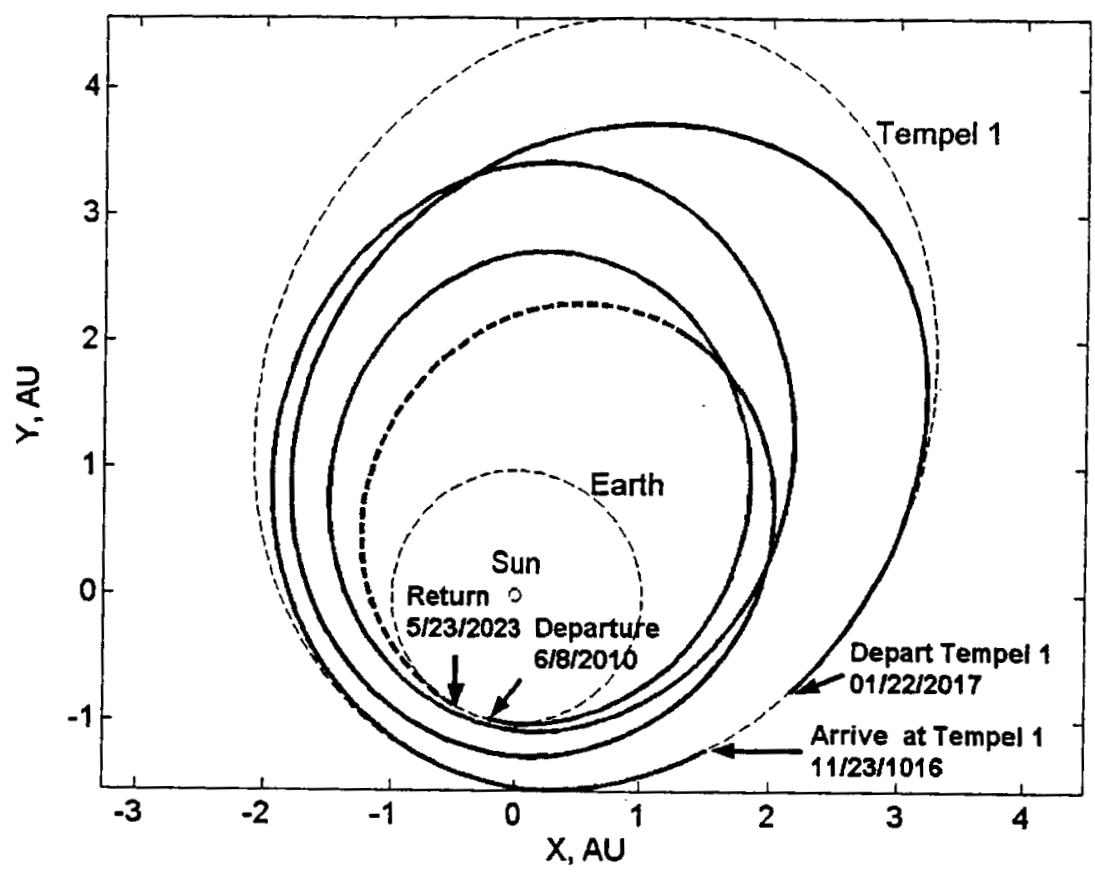

Figure 6. 13-yr Tempel 1 sample return mission with $12.5 \mathrm{~km} / \mathrm{s}$ Earth entry interface speed

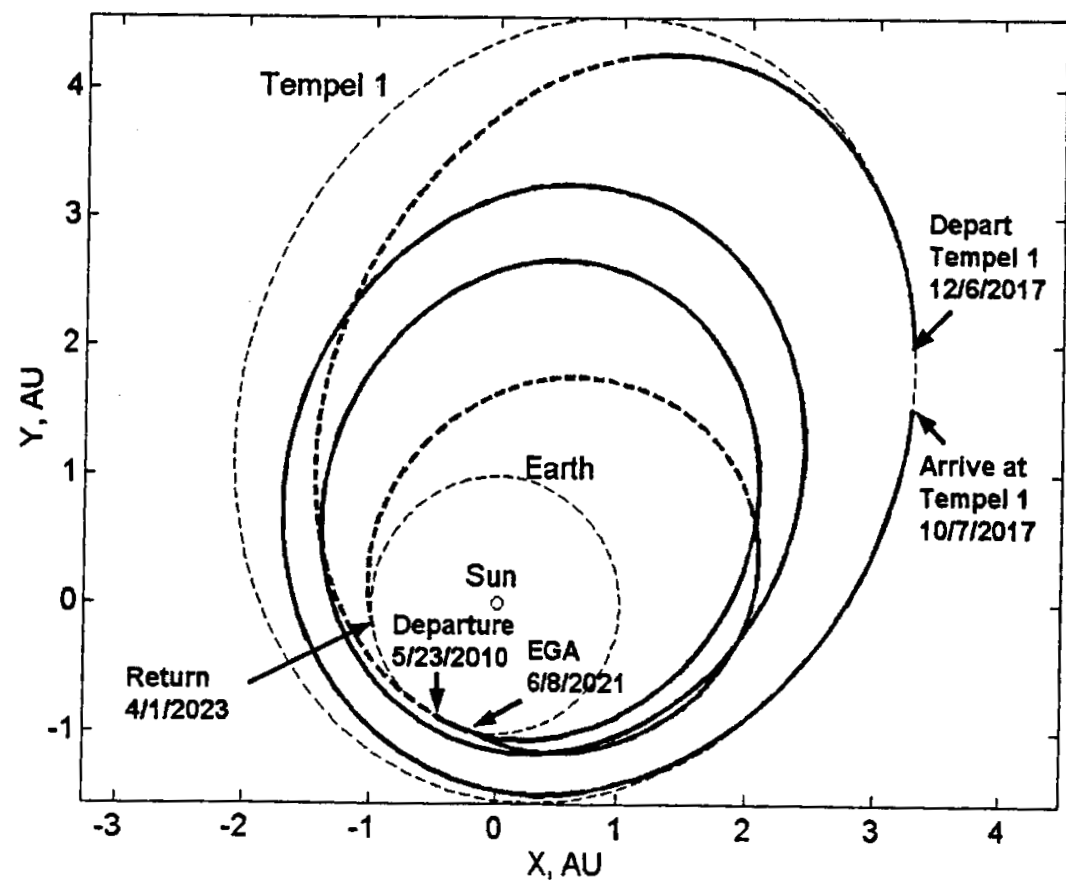

Figure 7. 13-yr Tempel 1 sample return mission with $12.5 \mathrm{~km} / \mathrm{s}$ Earth entry interface speed and Earth gravity assist during return leg. 
Figure 7 shows a trajectory option that uses an Earth gravity assist (EGA) during the return leg in order to further reduce the Earth entry interface speed. An EGA may or may not be feasible with the use of a nuclear power system, but this option is being presented for consideration and comparison. Note that the EGA follows a ballistic return arc, and that a relatively short powered arc is required after the EGA for proper entry conditions. It may be possible to jettison the REP system before the first EGA, and then use multiple phased EGAs to eventually set up the desired entry conditions.

Table 5 shows the mass benefits of including one EGA before reentry. Note that payload mass is improved when compared to the Atlas 401 cases without a gravity assist (Table 4), with the expense of additional trip time (the mission is now 13 years), and that solutions are possible with 750 and $1000 \mathrm{~W}$ of power.

Table 5. Optimal sample return missions using the Atlas 401 and Earth gravity assist for further reduced Earth entry interface speed

\begin{tabular}{cccccccc}
\hline $\begin{array}{c}\text { Initial } \\
\text { Power } \\
(\mathbf{W})\end{array}$ & $\begin{array}{c}\text { Entry } \\
\text { Speed, } \mathbf{V}_{\text {EI }} \\
(\mathbf{k m} / \mathbf{s})\end{array}$ & $\begin{array}{c}\mathbf{C}_{\mathbf{3}} \\
\left(\mathbf{k m}^{2} / \mathbf{s}^{2}\right)\end{array}$ & $\begin{array}{c}\text { Launch } \\
\text { Date }\end{array}$ & $\begin{array}{c}\text { Trip Time } \\
(\mathbf{y r s})\end{array}$ & $\begin{array}{c}\mathbf{m}_{\mathbf{0}} \\
(\mathbf{k g})\end{array}$ & $\begin{array}{c}\mathbf{m}_{\text {prop }} \\
(\mathbf{k g})\end{array}$ & $\begin{array}{c}\text { Payload } \\
(\mathbf{k g})\end{array}$ \\
\hline 750 & 12.5 & 38 & $5 / 23 / 2010$ & 12.87 & 1549 & 613 & 217 \\
1000 & 12.5 & 35 & $5 / 20 / 2010$ & 12.97 & 1654 & 547 & 277 \\
1000 & 13.0 & 35 & $5 / 20 / 2010$ & 13.00 & 1655 & 541 & 282 \\
\hline
\end{tabular}

Lastly, Table 6 presents 6-yr mission solutions using the Atlas 551 for a range of reduced Earth entry interface speed. Only for the $1000 \mathrm{~W}$ power case was a reduced entry speed solution found. It is only possible to reduce entry speed to $14 \mathrm{~km} / \mathrm{s}$ using the 6-yr mission profile with the Atlas 551 .

Table 6. Optimal sample return missions using the Atlas 551, initial power level of $1000 \mathrm{~W}, 6-\mathrm{yr}$ mission time, and reduced $V_{E I}$

\begin{tabular}{ccccccc}
\hline $\begin{array}{c}\text { Entry } \\
\begin{array}{c}\text { Speed, } \\
(\mathbf{k m} / \mathbf{s})\end{array}\end{array}$ & $\begin{array}{c}\mathbf{C}_{\mathbf{3}} \\
\left(\mathbf{k m}^{2} / \mathbf{s}^{2}\right)\end{array}$ & $\begin{array}{c}\text { Launch } \\
\text { Date }\end{array}$ & $\begin{array}{c}\text { Trip } \\
\text { Time } \\
(\mathbf{y r s})\end{array}$ & $\begin{array}{c}\mathbf{m}_{\mathbf{0}} \\
(\mathbf{k g})\end{array}$ & $\begin{array}{c}\mathbf{m}_{\text {prop }} \\
(\mathbf{k g})\end{array}$ & $\begin{array}{c}\text { Payload } \\
(\mathbf{k g})\end{array}$ \\
\hline 15.5 & 61 & $4 / 24 / 2010$ & 6.12 & 1953 & 869 & 247 \\
15.0 & 61 & $4 / 24 / 2010$ & 6.13 & 1959 & 907 & 225 \\
14.5 & 61 & $5 / 20 / 2010$ & 6.13 & 1972 & 1000 & 170 \\
14.0 & 61 & $5 / 22 / 2010$ & 6.14 & 1967 & 1114 & 91 \\
\hline
\end{tabular}

\section{Conclusions}

Several designs for a comet sample return mission using an advanced REP based ion propulsion system have been obtained. A set of mission and system parameters were varied with the goal of quantifying their impact on total mission payload. Mission parameters considered include trip-time and Earth return entry interface speed of the sample return system. System parameters varied include launch vehicle, power level of spacecraft at beginning of mission, and thruster specific impulse.

For the baseline $750 \mathrm{~W}$ case, the specific impulse of the EP thruster was optimized so that the trajectories exhibit an approximately 12 year trip time for the Atlas 401 launch vehicle. An initial quick-look did not show significant improvements for the higher power level of $1-\mathrm{kW}$. Work in addition to the baseline work was later performed in support of graduate studies at the University of Missouri. In this additional work, improvement was found in transfer time to approximately 11-yr total flight time for the same Atlas 401 launch vehicle for each of the 3 power levels investigated. Further, cases were found providing a maximum science payload mass for a launch energy of $C_{3}=33 \mathrm{~km}^{2} / \mathrm{s}^{2}, C_{3}=36 \mathrm{~km}^{2} / \mathrm{s}^{2}, C_{3}=41 \mathrm{~km}^{2} / \mathrm{s}^{2}$ for system power level of $1000 \mathrm{~W}, 750 \mathrm{~W}$, and $500 \mathrm{~W}$ respectively. A power level of at least $1000 \mathrm{~W}$ and trip-time of approximate 11 years was required to obtain a total science payload of approximately $280 \mathrm{~kg}$ for the smaller Atlas 401 launch vehicle. The larger Atlas 551 launch vehicle yielded a science payload increase to approximately $530 \mathrm{~kg}$ for the case of $1000 \mathrm{~W}$ of power and a 12 year trip time, and nearly $250 \mathrm{~kg}$ of total payload for the case of $1000 \mathrm{~W}$ of power and a 6 year trip time. For the Atlas 401 launch vehicle cases, the outbound and inbound legs of the missions optimized to a single specific impulse 
generally in the Hall ion thruster range. The Atlas 551 cases tended to optimize generally in the Hall ion thruster range for both outbound and inbound legs of the mission.

\section{Acknowledgments}

The work described in this paper was funded in whole or in part by the NASA Science Mission Directorate's Radioisotope Power System program. The study was conducted by the In-Space Propulsion Technology Office at Marshall Space Flight Center in Huntsville, AL.

\section{References}

${ }^{1}$ Rayman, M.D., and Lehman, D.H., "NASA's First New Millennium Deep-Space Technology Validation Flight," International Academy of Astronautics, IAA Paper L-0502, April 1996.

${ }^{2}$ Koppel, C. R., Marchandise, F., Estublier, D., and Joliver, L., The SMART-1 Electric Propulsion Subsystem In Flight Experience, AIAA 2004-3435, 40 ${ }^{\text {th }}$ AIAA/ASME/SAE/ASEE Joint Propulsion Conference \& Exhibit, July 11-15, 2004, Fort Lauderdale, FL

${ }^{3}$ Kuninaka, H., Nishiyama, K., Shimizu, Y., and Toki, K., Flight Status of Cathode-Less Microwave Discharge Ion Engines Onboard HAYABUSA Asteroid Explorer, AIAA 2004-3438, 40 $0^{\text {th }}$ AIAA/ASME/SAE/ASEE Joint Propulsion Conference \& Exhibit, July 11-15, 2004, Fort Lauderdale, FL

${ }^{4}$ Noble, Robert J. Radioisotope-Powered Electric Propulsion of Small Payload for Regular Access to Deep Space, AIAA-93-1897.

${ }^{5}$ Noble, Robert J. Radioisotope Electric Propulsion for Small Robotic Space Probes, Journal of The British Interplanetary Society, Vol. 49, pp. 455-468, 1996.

${ }^{6}$ Noble, R. Radioisotope Electric Propulsion of Sciencecraft to the Outer Solar System and Near-Interstellar Space, Nuclear News, Nov. '99, Vol. 42, No. 12, American Nuclear Society.

${ }^{7}$ Fiehler, D. and Oleson, S., Radioisotope Electric Propulsion Missions Utilizing a Common Spacecraft Design, IAC-04-IAA.3.6.4.01, International Astronautical Congress, 2004, Oct. 4-8, 2004, Vancouver, BC, Canada

${ }^{8}$ Fiehler, D. I. and Oleson, S. R., Neptune Orbiters Utilizing Solar And Radioisotope Electric Propulsion, AIAA 2004-3987, 40 ${ }^{\text {h }}$ AIAA/ASME/SAE/ASEE Joint Propulsion Conference \& Exhibit, July 11-15, 2004, Fort Lauderdale, FL

${ }^{9}$ Oleson, S., Benson, S., Patterson, M., and Schreiber, J. "Radioisotope Electric Propulsion for New Frontiers Class Missions", IEPPC 2003-0137, 28 ${ }^{\text {th }}$ International Electric Propulsion Conference, March 17-21, 2003, Toulouse, France.

${ }^{10}$ Oh, D., Cupples, M. L., Belcher, J., Witzberger, K., Fiehler, D., "Evaluation of Radioisotope Electric Propulsion for Selected Interplanetary Science Missions", Paper to be delivered at the 2005 International Electric Propulsion Conference.

"Kluever, C.A., "Optimal Interplanetary Trajectories by Direct Method Techniques," Journal of the Astronautical Sciences, Vol. 45, No. 3, 1997, pp. 247-262.

${ }_{12}$ Pouliot, M.R., "CONOPT2: A Rapidly Convergent Constrained Trajectory Optimization Program for TRAJEX," Convair Div., General Dynamics, GDC-SP-82-008, San Diego, CA, Jan. 1982.

${ }^{13}$ Standish E.M., JPL Planetary and Lunar Ephemerides, URL: ftp://ssd.jpl.nasa.gov/pub/eph/export/README, [cited on December 7, 2004]. 